\title{
Family-Based Caregiving: Does Lumping Asian Americans Together Do More Harm Than Good?
}

\author{
Suryadewi E. Nugraheni, MD, MA \\ University at Albany, State University of New York, Albany, New York, United States \\ (iD https://orcid.org/0000-0002-0330-2835 \\ Julia F. Hastings, PhD, MSW \\ University at Albany, State University of New York, Albany, New York, United States \\ (iD) https://orcid.org/0000-0002-2262-2279
}

Contact: snugraheni@albany.edu

\section{Abstract}

Asian American family caregivers have gained increased attention due to the need to provide life-sustaining aid at home given the rising numbers of older adults. This article reflects upon caregiving-related research studies that have overlooked the circumstances Asian American caregivers bring to the home-care context. Policies written to address community needs tend to omit the social circumstances many Asian American caregivers must face when trying to take advantage of programs and services. For example, the eligibility requirements fail to recognize distinctive cultural values embedded within the caregiving processes. Further, most Asian American data is aggregated. Aggregating data by ethnicity limits an accurate portrayal of social circumstances. The health effects developed from caregiving demands tend to remain unaddressed and the distribution of goods and essential services generally does not reach many home-based Asian American caregivers in need. This text examines a within-group perspective to uncover sociocultural dimensions influencing caregiving. Different perspectives include those of government and community agencies, research institutions, and data-driven websites (e.g., U.S. Census Bureau). Role Strain Theory and Role Enhancement Theory are discussed. This article explores critical issues such as the health impacts of caregiving demands, Asian American identity conflicts, and United States caregiving policy's lack of acknowledgment of Asian American diversity. To begin making corrections to misleading assumptions about Asian Americans and their culture, the article closes with how researchers need to accept the heterogeneity of Asian Americans and provide a foundation for culturally appropriate policies and programs that can enhance caregivers' quality of life.

Keywords: Asian Americans, caregivers, culture, health, policy, Role Strain Theory, Role Enhancement Theory, ProQuest, Google Scholar

Date Submitted: July 21, 2020 | Date Published: March 17, 2021

\section{Recommended Citation}

Nugraheni, S. E., \& Hastings, J. F. (2021). Family-based caregiving: Does lumping Asian Americans together do more harm than good? Journal of Social, Behavioral, and Health Sciences, 15, 87-103. https://doi.org/10.5590/JSBHS.2021.15.1.07 


\section{Introduction}

Family-based caregivers typically hold round-the-clock responsibilities that include providing emotional, social, spiritual, and financial support, as well as decision making and assistance with physical tasks (National Association of Social Workers [NASW], 2010). In addition to multifaceted caregiving roles, caregivers also have other personal responsibilities, such as working and/or raising children (Schulz \& Eden, 2016). The Asian American family, as well as culturally-based caregiving, feature sociocultural characteristics that are ethnically distinct from one to the next, which adds to the complexity of the exploration of the issues. Our study about caregiving involves three areas:

- First, we explore the impacts of the caregiving process on health.

- Next, we discuss Asian American identity conflicts.

- Lastly, we identify the inadequacy of U.S. caregiving policies intended to support Asian American caregivers.

By exploring and highlighting demographic characteristics and crosscutting issues of Asian American caregivers, this article aims to highlight the detriments to considering Asian Americans as a monolithic group. It is important to recognize the diversity within Asian American communities and to point out how caregiving policy fails to recognize the role citizenship plays in caregiving service receipt.

\section{Asian American Demographic Characteristics}

More than 20 million individuals represent a diverse group of Asian Americans, with a majority from East and Southeast Asia and India. Eighty-five percent of all Asian Americans are accounted for by Chinese, Filipino, Indian, Vietnamese, Korean, and Japanese individuals (López et al., 2017; Kitano \& Nakaoka, 2001). Asian Americans are the fastest-growing ethnic group in the U.S. and are located throughout the United States, with the most rapid growth occurring between 2000 and 2015, at a rate of $72 \%$. Along with much ethnic group difference, considerable variation in English proficiency, educational attainment, and citizenship exists (López et al., 2017). Unfortunately, efforts to collect and analyze data by each Asian American ethnic group remain absent from major data sources due to historical practices to aggregate Asian Americans as one ethnic entity. Consequently, Asian American ethnic distinctions remain largely invisible to recognized need.

\section{Who Are Asian Americans?}

Today, the U.S. census recognizes 25 Asian American ethnic groups suggesting heterogeneity and not homogeneity (Hoeffel et al., 2012). Researchers, service professionals, and stakeholders continue to aggregate different Asian ethnic groups to accommodate statistical procedures (Kitano \& Nakaoka, 2001). A few arguments appearing in the literature focus on inadequate sample sizes along with the argument that each Asian American ethnic group is relatively small. Unfortunately, too small sample size statements often lead to omission in surveys and epidemiologic research (Holland \& Palaniappan, 2012). This omission or the classification into a single Asian American group results in no scientific data on major health outcomes from the National Health and Nutrition Examination Survey (NHANES) or National Health Interview Survey (NHIS) and little to no information on caregiver needs from the National Study of Caregiving (NSOC). Common explanations include an inability to translate national surveys into multiple languages, and data collection sample efforts yielded no Asian American individuals. Similarly, the literature often reflects vital national statistics data collection efforts utilizing only English or Spanish translations, despite more than half of the Asian American population being foreign born (U.S. Census Bureau, 2017) and only $44 \%$ having limited English ability (Radford, 2019). This highlights the fact that $56 \%$ of Asian immigrants can be survey 
Nugraheni \& Hastings, 2021

participants in English. Therefore, the only excuse for why many Asian Americans continue to be excluded in surveys and from sampling procedures appears to be based on erroneous assumptions that may not represent contemporary Asian American populations (Holland \& Palaniappan, 2012). Sample aggregation in survey methods today seems to rely on past methods and the need to maintain the status quo in order to make historical comparisons (Ahmad \& Weller, 2014).

Political concerns also stand as a reason for aggregating data of different Asian American groups (Kitano \& Nakaoka, 2001). Labeling persons Asian American is considered strategic political usage. Asian Americans are identified as a group of individuals with origins from Asia living in the United States who share an interrelated history of immigration, racial discrimination, and political agenda (Kandil, 2018). Asian American is also referred to as a large, diverse community. The term Asian American can be empowering by bringing together individuals of different Asian origins. Yet, by using one term to define all Asian subgroup populations, individual and cultural uniqueness is omitted; the statistical strength in numbers only helps in analysis technique, but not to explain or solidify positioning as a population with unique, disparate health needs (Kandil, 2018).

Data aggregation also overlooks the diversity of immigration history, citizenship status, culture, and political agenda of Asian American ethnic groups. Considering views from diverse Asian ethnic groups is increasingly needed over time because Asian American populations continue to grow. The U.S. Census Bureau's decennial surveys from 1900 to 1970 indicated the total Asian American population remained extremely low, constituting less than $1 \%$ of the total U.S. population (Hobbs \& Stoops, 2002). The latest decennial census in 2010 found the proportion of Asian Americans had increased to 5.61\% of the total U.S. population (Hoeffel et al., 2012). Approximately 94\% of the total Asian American population comprises 19 Asian American ethnic groups (López et al., 2017). Chinese Americans, Filipino Americans, Vietnamese Americans, Korean Americans, and Japanese Americans are among the ethnic groups with more than 1 million members, while Indonesian Americans and Bangladeshi Americans represent the groups with less than 1 million members (López et al., 2017; U.S. Census Bureau, 2017). Although the aggregation of all Asian American ethnic groups only makes up a small percentage of the U.S. total population, the constant growing numbers call for clearer distinguishing of Asian American ethnic groups than has previously appeared in literature and research.

\section{The Role of Asian Values in Asian American Caregivers}

Following the same trajectory of Asian Americans in the U.S., the number of Asian American elderly population is also increasing. The proportion of the Asian American aging population grew from 3.4\% in 2010 to $4.2 \%$ of Americans age 65 years and older in 2016 (Roberts et al., 2018; West et al., 2014). The growing rates of the Asian American elderly population also align with the increasing proportion of Asian American caregivers. The percentage of Asian Americans holding a caregiving role increased from 15\% in 2004 to $19.7 \%$ of the Asian American population in 2015 (The National Alliance for Caregiving and the AARP Public Policy Institute [NAC and AARP], 2004, 2015). The growing rates of the Asian American elderly population and Asian American caregivers give rise to the need to focus on the diversity of Asian American caregivers who care for the elderly.

Asian American caregivers may share similar caregiving responsibilities with family caregivers of other racial/ethnic groups. However, each Asian population (e.g., Chinese, Japanese, and Filipino) embraces familism, religion, and culture, and assimilates to the U.S. customs differently, thereby affecting their caregiving practices. Generally, Asian American caregivers endorse familism and filial obligations (Chun et al., 2002). Familism implies strong family bonds and family solidarity (Chun et al., 2002; Knight \& Sayegh, 2010). Filial obligation suggests children should honor their parents' care by returning the care for them as the parents get older and cannot live independently (Chun et al., 2002; Lee \& Smith, 2012). Hence, caregiving for the elderly is a natural and expected stage among Asian Americans (Braun \& Browne, 1998; Miyawaki, 2016; Vega, 2014). 
Caregivers of Asian backgrounds differ from one group to another in expressing filial obligations and family relationships in their daily lives. For instance, according to Filipino American caregivers, family relationship means having a close-knit immediate family and expanding their close relationship to their large extended family to receive socioemotional and economic support (Paik et al., 2016). For many Chinese American caregivers, familism can be interpreted as keeping their privacy (e.g., issues in caregiving) within their families (McLaughlin \& Braun, 1998). Japanese Americans perceive filial obligation as a reciprocal relationship within a social network (Takamura, 1991). Thus, Japanese American caregivers believe that they would receive care in the future due to their present care for the elderly (McLaughlin \& Braun, 1998).

Similar to familism and family relationship, religion also influences the perceptions of caregiving across Asian American ethnic caregivers. Confucianism, Buddhism, Islam, Christianity, and Taoism are among religions that guide caregiving processes unique to a particular Asian American ethnic group(s). For example, Confucianism impacts the caregiving practices of Korean American caregivers (Lee \& Smith, 2012). Confucianism is a social and ethical philosophy that highlights familism, family cohesion, and moral understanding (Lee \& Smith, 2012). According to Confucian values, elder care is provided by the first-born son and his wife (Braun \& Browne, 1998; Lee \& Smith, 2012). However, in caring for the elderly, Korean American family and community play a central role that could be interpreted as pressure points for the caregivers (Lee \& Smith, 2012). Vietnamese Americans, in another example, practice Confucianism and Buddhism. For Vietnamese Americans, Confucianism and Buddhism teach that if the children care for their parents, both the parents and the children will reincarnate at a higher level in their future lives (McLaughlin \& Braun, 1998). Based on the few examples presented here, each Asian American ethnic group shows uniqueness in religious wisdom and caregiving attitudes that are substantially different from one another.

Cultural diversity also affects differences in Asian American caregiving perspectives. For instance, Filipino Americans believe their health issues are in God's hands, a concept called bahala na (Braun \& Browne, 1998). In addition, Filipino Americans also endorse Filipino cultural values such as hiya or shame, utang na loob or a debt of gratitude from children to their parents, and pakikisama or harmony. Japanese Americans also may conceal their health issues or their family difficulties, called haji or shame (Chu \& Sue, 2011).

Caregiving practices are also influenced by assimilation processes. According to the assimilation theory, the longer immigrants live in their adopted country, the more integrated their behavior and values into the majority group (Gordon, 1964). Similarly, the longer immigrants live in the United States, the poorer their health becomes. This is known as the healthy immigrant effect (Flores \& Brotanek, 2005). Based on the assimilation theory, first-generation or non-U.S.-born Asian Americans preserve their respective culture (e.g., providing longer caregiving duration) more than the later generations or U.S.-born Asian Americans (Miyawaki, 2016). Moreover, the second or later generations are more likely to utilize caregiving supports such as English-speaking, in-home caregivers, similar to their White individual counterparts (Miyawaki, 2017).

Heterogeneity of religious values and perceptions of caregiving in several Asian American ethnic groups are highlighted. Filial piety, religious wisdom, and cultural perspectives affect different caregiving attitudes of each Asian American caregiver ethnic population. Generalizing Asian American caregivers as a large racial group with similar Asian values may mask ethnic group-specific characteristics.

\section{Literature Collection Process}

The scope of literature reviewed is based on numerous sources. We analyzed books with topics including caregiving, aging, family, social services, Asian Americans, and acculturation. In addition, journal articles with keywords such as Asian Americans, caregiving, health, immigration, and culture were analyzed. We also reviewed websites and reports of government agencies and research institutions, such as the U.S. Census 
Bureau, Pew Research Center, and the Family Caregiver Alliance (FCA). Information retrieved from community agencies that offer caregiving services for Asian Americans, such as Asian Community Center Senior Services and Chinese Community Center, were additionally explored. Lastly, newspapers such as The New York Times and the Los Angeles Times were examined for articles that discussed Asian American issues.

\section{Crosscutting Issues of Caregiving}

Although much of the past research and literature has focused on Asian American caregivers, a fundamental issue that has not been adequately addressed is that a considerable number of studies continue to observe Asian American caregivers as one large racial entity. Aggregating Asian American caregivers into one racial category, when in fact the population groups represent several countries, leads to three crosscutting issues related to the impacts on caregiving. The crosscutting issues can be categorized as the health impacts of caregiving demands, conflicts of Asian American identity, and a lack of adequate U.S. caregiving policy to accommodate the mixed citizenship in families. Understanding the three priority topics may allow researchers to help recognize the complexity and the nature of the caregiving process faced by Asian American caregivers and move forward in improving caregivers' quality of life.

\section{Issue 1: The Impacts of Caregiving on the Health of Asian Americans}

This article argues that treating groups of Asian American ethnic caregivers alike, when, in fact, the groups are distinct, demonstrates cultural insensitivity. Moreover, the exclusion of ethnic characteristics of Asian American caregivers can undermine the health status of each caregiver group. Choosing between caregiving and personal needs, defining perceptions of old age, and utilizing health care services are ethnically related factors that influence the Asian American caregiving process and can influence caregivers' mental health. If caregivers cannot manage their mental health well, stress may occur.

Unlike the traditional family model that suggests women hold the role of a homemaker, many Asian American couples work outside the home to fulfill their financial needs (Vega, 2014). The growth in female labor force participation affects women who are seen as the primary caregivers in many Asian American subgroups, such as Vietnamese Americans and Chinese Americans (Vega, 2014). On the one hand, the high participation of Asian American women in employment endorses the stereotypic views of Asian Americans as being selfsufficient and successful. On the other hand, the new role impacts Asian American women's ability to provide care for their elderly parents (Berkman, 2006). Approximately $21 \%$ of caregivers are able to reduce their work hours (AARP, 2014). However, due to competing demands, some Asian Americans choose to stop working and shift their time to being full-time caregivers to fulfill filial piety (Vega, 2014). Caregivers may experience stress when they cannot manage their dual responsibilities of work and care for their elderly (Feinberg, 2016).

Certain Asian Americans also hold a stereotypic perception of old age. Similar to those of the country of origin, some Chinese Americans and Vietnamese Americans believe that mental confusion and decline in memory of the elderly are considered normal (Liu et al., 2008). This normalization view of aging may delay help seeking from health professionals. A late diagnosis of memory impairment for elderly family members will often lead to caregiver stress because of strenuous caregiving responsibilities.

Different Asian American ethnic caregivers hold many perspectives in utilizing health care services. A substantial number of Chinese Americans and Vietnamese Americans still incorporate traditional medicine into caregiving activities (Berkman, 2006; McLaughlin \& Braun, 1998). Filipino American caregivers may also use home remedies. In addition, Filipino Americans use prayer and faith healing alongside western intervention (Braun \& Browne, 1998). Korean Americans are aware that a nursing home could be an option to care for their parents. Nonetheless, placement in a nursing home may not be a solution because they want to avoid unfavorable judgment from their Korean American community (Lee \& Smith, 2012). Thus, the 
mainstream caregiving system utilizing Western medicine or sending the elderly family member to a senior institution may not be culturally congruent with Asian American beliefs.

Not only do caregiving practices affect mental health, they can also impact the physical health of Asian American ethnic groups. Kim and Knight (2008) conducted a study that compared Korean American caregivers to non-caregivers in order to analyze their cortisol levels, blood pressure, and self-reported health. Higher levels of cortisol indicate increased psychological stress (Kim \& Knight, 2008). Although stress had no significant effect on self-reported health, the analyses indicated caregiver status had adverse effects on Korean American caregivers' blood pressure and cortisol levels (Kim \& Knight, 2008).

Holland et al. (2010) also observed cortisol levels by comparing Chinese American caregivers. Specifically, Holland et al. (2010) observed whether having a belief in Asian values has effects on cortisol levels, depressive symptoms, self-efficacy, and positive perceptions of caregiving of Chinese American caregivers. The finding indicated Chinese American caregivers who strongly endorsed Asian values were more likely to have normal cortisol levels than those who did not strongly adhere to Asian values. Further, the findings demonstrated greater endorsement in Asian values was associated with lower depressive symptoms, higher self-efficacy, and more positive perceptions of caregiving (Holland et al., 2010).

Two opposing theories also explain the caregiver's health. The Role Strain Theory (RST) by Goode (1960) suggests that individuals may have difficulties in carrying out their family obligations, in other words, caregiving. As a result, strain, worry, and anxiety may occur. By contrast, the Role Enhancement Theory (RET) by Sieber (1974) indicates that having accumulation obligations may enrich individuals' personality and integrity. Given the RET, caregiving practices among Asian Americans strain family relationships because of conflicting perspectives between the caregiving system and the older adult's expectations (Apesoa-Varano et al., 2017). However, looking deeply at ethnic groups, caregiving may encourage psychological functioning. For example, for some Chinese Americans, caregiving can be rewarding because it is understood as a family obligation that enhances family relationships (Xu et al., 2017).

The RST indicates that strain in fulfilling multiple demands is normal and suggests that the social system can help decrease individuals' strain (Goode, 1960). Social support is also explained by the RET and can enhance caregiving capacities (Apesoa-Varano et al., 2017; Sieber, 1974). It is expected that caregivers would receive and seek support from their families, communities, and other social institutions to reduce their burden and enhance caregiving performance (Chun et al., 2002; Shih et al., 2019; Miyawaki, 2017). However, ethnic groups and stigma associated with an illness can create variations in Asian American caregivers' support systems (Apesoa-Varano et al., 2017; Miyawaki, 2016). For instance, the stigma associated with dementia could prevent Vietnamese American caregivers from receiving support from families (Meyer et al., 2015). Thus, a lack of family support for Vietnamese American caregivers of individuals with dementia could increase their tension and decrease their caregiving function.

It is evident that the impacts of caregiving on health may be experienced differently by Asian American caregivers of different ethnic groups. The results of previous studies demonstrated that Asian culture and values contribute to the wellbeing of Asian American caregivers. Ignoring group-specific sociocultural factors can delay access to adequate interventions and can hinder the possibility of improving the quality of life for Asian American caregivers.

\section{Issue 2: Identity Conflicts as Asian Americans}

Asian American caregivers may experience identity conflicts that can influence caregiving roles and the state of caregivers' health. According to Kim (1981), identity conflict is "when an individual perceives certain aspects or attributes of him-herself which s/he rejects simultaneously" (p. 1). Kim (1981) further explains that identity conflict in Asian Americans does not occur because of a lack of awareness of Asian ethnic self. Rather, 
Asian Americans' identity conflict arises due to how Asian Americans feel and value their ethnic self in the extensive White culture (Kim, 1981).

Identity conflict may emerge as a result of acculturation, in which Asian immigrants may have acculturated and become familiar with the American way of life (Chun et al., 2002; Miyawaki, 2016; Takeuchi et al., 2007). Acculturation is "the extent to which individuals learn the values, behaviors, lifestyles, and language of the host culture" (Zane \& Mak, 2002, p. 39). Asian immigrants were born surrounded by their Asian culture and values, such as prioritizing family harmony over individual needs and satisfaction (Walton \& Takeuchi, 2010). They also speak with their ethnic language and utilize Eastern medicines to fulfill their caregiving responsibilities (Vega, 2014). After immigration, immigrants' learning about the new culture and social networks may be substantially different from the their Asian traditions and social system (Takeuchi et al., 2007; Suinn et al., 1987). In the United States, Asian immigrants need to learn to be more egalitarian and independent (Walton \& Takeuchi, 2010) and may also face pressure to acquire English as their new language (Xia et al., 2013). Yet, at the same time, the demands to sustain the attachment to Asian culture and norms may remain strong (Takeuchi et al., 2007). As a result, the differences between Asian daily living and the common U.S. day-to-day life may contribute to an identity conflict for foreign-born individuals.

On the other hand, U.S.-born Asian Americans were raised with customs where understanding Western culture is natural (Kurien, 2018). For example, U.S.-born Asian Americans may not face a language barrier and be accustomed to the U.S. schooling system and social network (Takeuchi et al., 2007). However, U.S.born Asian Americans also face an identity conflict. Being born in America tends to label U.S.-born individuals as not being Asian enough or not being American enough (Shyong, 2020). Another issue emerged in which each family member may not have the same acculturation rate. Takeuchi et al. (2007) explain that the longer individuals reside in a new place, the more familiar they would be with the new culture, language, and lifestyles. Conversely, the older an individual was when moving to the U.S., the less acculturated the individual became to the adopted country (Suinn et al., 1987). Compared to the previous generation or the older adults, U.S.-born Asian Americans may have fewer feelings of family obligations and cohesiveness. Consequently, the incompatibility of family and caregiving expectations between two generations may cause family instability, identity conflict, and acculturation stress for U.S.-born Asian Americans (Meyer et al., 2015; Shih et al., 2019; Walton \& Takeuchi, 2010).

It is evident that foreign-born status and the acculturation process contribute to different perceptions of Asian culture in caregiving, leading to identity conflict. Consequently, identity conflict negatively impacts the quality of mental health of Asian Americans, such as emotional distress and depressive symptoms and decreasing daily life outcomes, such as academic and work performance (Kim, 1981; Miyawaki, 2016; Xia et al., 2013). Since identity conflicts may occur across ethnic groups, conducting research by collapsing Asian Americans into one large group may hinder the opportunities to uncover the true reasons for health problems among Asian American caregiving individuals.

\section{Issue 3: A Lack of U.S. Policy Supports for Asian American Caregivers}

Despite the fact that the rate of Asian American caregivers is rapidly increasing, current federal U.S. policies have lagged in adaptation to need and other issues specifically facing Asian American family caregivers (Chen \& Philip, 2009; James et al., 2016; Schulz \& Eden, 2016). Individuals from Asian countries migrated to the U.S. for different reasons. While many immigrants from Vietnam, Laos, and Cambodia moved to the U.S as refugees, other immigrants from Japan and China more likely came to study or work (López et al., 2017; Xia et al., 2013) and, as a result, vary in English language ability.

Further, in 2017, one in seven immigrants from Asia was undocumented (AAPI Data, 2017). Moreover, the percentages of undocumented immigrants from Asia of the total unauthorized U.S. population increased from 13.3\% in 2010 to $15.9 \%$ in 2017 (Center for Migration Studies [CMS], n.a.). Looking at the Asian countries of 
origin, of the total undocumented Asians residing in the U.S., India leads with the largest numbers of undocumented persons (26\%), followed by China (22\%), the Philippines (14\%), South Korea (10\%), and Vietnam (7\%) (AAPI Data, 2017). Thus, U.S. policies not only need to pay attention to the immigration status of individuals from Asian countries but also should recognize social, historical, and political characteristics that drive the migration of each ethnic group.

According to the Illegal Immigration Reform and Immigrant Responsibility Act of 1996 (IIRIRA, 1996), nonU.S. citizens are not eligible to receive benefits from federal programs (Broder et al., 2015). Specifically, Sec. 504. entitled Procedures for Requiring Proof of Citizenship for Federal Public Benefits of IIRIRA (1996) states:

Not later than 18 months after the date of the enactment of this Act, the Attorney General, in consultation with the Secretary of Health and Human Services, shall also establish procedures for a person applying for a Federal public benefit (as defined in section 401(c)) to provide proof of citizenship in a fair and nondiscriminatory manner. (IIRIRA 1996, Sec. 504)

In sum, the IIRIRA of 1996, Sec. 504 indicates that to receive the federal public benefits, all individuals are required to show proof of U.S. citizenship. Undocumented immigrants and non-U.S. citizens with proper documentation are excluded from participating in programs (Broder et al., 2015). Since the majority of Asian Americans were foreign-born (U.S. Census Bureau, 2017) and many of them are undocumented (AAPI Data, 2017), policy implementations disproportionately exclude Asian Americans.

\section{Caregiving Policies and Programs}

The Child and Dependent Care Credit (CDCTC) and the National Family Caregiver Support Program (NFCSP) are among the federal policies from which undocumented or unauthorized immigrants may not be eligible to receive benefits.

\section{The Child and Dependent Care Credit (CDCTC)}

The CDCTC is a refunded tax credit that was passed by Congress under the Taxpayer Relief Act of 1997 (Taxpayer Relief Act of 1997, 1997). Family caregivers of a qualified individual can claim the federal tax credit for their paid caregiving expenses up to \$3,000 per care-recipient per year (Internal Revenue Service [IRS], 2018). Among the criteria that caregivers may receive the tax credit are when a care-recipient is a child under the age of 13 years or a spouse or an individual with physical or mental difficulties who cannot provide selfcare and lives with the caregiver for more than half of the year (IRS, 2018; James et al., 2016).

The implementation of the CDCTC creates issues for Asian American ethnic caregivers. The care-dependent should live with the caregiver for at least six months (IRS, 2018; Taxpayer Relief Act of 1997, 1997). However, for Korean Americans, even though the first son and his wife live in a separate residence with the parent, they are the primary caregivers due to their hierarchical family relationships and cultural norms (Lee \& Smith, 2012). As a result, the residency requirement may not support Korean Americans' caregiving practices.

Next, family caregivers will not be eligible to receive the tax credit if their parents reside in a nursing home or senior institution (James et al., 2016). Literature and research report that Asian Americans underutilize health care services. For example, Vietnamese American caregivers do not want to put the elderly into a nursing home because it contradicts their cultural values and the older adults' limited English proficiency (Vega, 2014). Vietnamese American caregivers also expressed a lack of trust with respite care services (Meyer et al., 2015). However, some Asian American groups may use a health care institution under certain conditions. Although institutionalization for elderly with limited Activities of Daily Living is predominantly 
utilized by Non-Hispanic Whites (23.8\%), Korean Americans (18.8\%), Japanese Americans (16.6\%), and Chinese Americans (13.2\%) are the three highest Asian American groups that also use a senior institution for their elderly (Fuller-Thompson \& Chi, 2012).

Lastly, eligibility to claim credit is attached to the dependent, not the caregiver. Specifically, a caregiver cannot receive the credit if the care-recipient does not have a legal U.S. residency status (Glynn \& Fitz, 2012). Consequently, undocumented Asian American caregivers could not be eligible for CDCTC benefits if their elderly parents are also undocumented Asian Americans. CDCTC is also not useful for Asian American caregivers with a U.S. legal status when their elderly parents do not have the legal documents to live in the United States.

\section{National Family Caregiver Support Program (NFCSP)}

In 2000, the federal government enacted NFCSP under Title III-E of the Older Americans Act (OAA). The program delivers grants to states, regions, and agencies to assist family caregivers with various services (Administration for Community Living [ACL], 2019; James et al., 2016). The eligible services include service information for caregivers, assistance with gaining access for caregiving services, individual counseling, support group and training for caregivers, respite care, and limited supplemental services (ACL, 2019). Among the eligibility criteria to receive the services are that family caregivers be 18 years and older providing care for individuals 60 years and older or caregivers for individuals with Alzheimer's disease and related diseases regardless of age (ACL, 2019; James et al., 2016; National Family Caregiver Support Act, 2000).

NFCSP is the first and only federal policy specifically aimed at providing service for caregivers (Schulz \& Eden, 2016). In 2013, NFCSP provided counseling and training to more than 125,000 caregivers, respite services to more than 63,000 caregivers, and 1.15 million contacts for caregivers to gain access to the program (James et al., 2016). By using the services granted by NFCSP, caregivers can reduce their caregiving stress, anxiety, and stress, and, thus, decrease the need for institutional health care (ACL, 2019).

Asian American caregivers can experience health disparities due to the implementation of the NFCSP. Among Asian American aging agencies that receive grants from OAA or NFCSP are Asian Community Center Senior Services (ACCSV) in Sacramento, California; Greater Boston Chinese Golden Age Center (GBCGAC) in Boston, Massachusetts; and Chinese Community Center in Houston, Texas (ACCSV, 2019; Chinese Community Center, 2019; GBCGAC, 2012). However, not every state and every regional area have an Asian ethnic-related agency. Even if a culturally sensitive caregiver support program exists in a community, only a few Asian languages are available. For example, GBCGAC in Boston dedicates the program to Chinesespeaking caregivers (GBCGAC, 2012). Consequently, health disparities among Asian American ethnic caregivers may occur.

\section{Other Programs}

Moreover, each state, each county, and each agency may decide which services would be available (FCA, 2004). For instance, some agencies, such as GBCGAC, allocate federal dollars for respite care and transportation services (GBCGAC, 2012) and other agencies, such as the Chinese Community Center, give caregiving training (Chinese Community Center, 2019). As a result, some Asian American family caregivers may not receive the services they need.

Since the policy allows states to design their own eligibility requirements (Administration for Community Living [ACL], 2017), some states require applicants to identify their citizenship status. For example, both the caregiver and the care-recipient are required to follow the assessment protocol and indicate their citizenship statuses to apply for Caregiving Support Services of Kentucky (Kentucky Cabinet for Health and Family Services [CHFS], 2009). Since the citizenship status information is needed for the Caregiving Support 
Services, it can be argued that Asian Americans without proper documentation are afraid that their immigration status can be exposed to the immigration and welfare offices. Hence, NFCSP may not adequately provide support and services for Asian American caregivers due to issues such as the fear and concerns of undocumented immigrant families.

NFCSP is the only policy that is designed to assist family caregivers. The availability of culturally sensitive agencies, the flexibility of states and regions in allocating the funding, and the variety of eligibility requirements may not effectively close the gap among Asian American family caregivers' health status and quality of life. Asian American caregivers from certain ethnic groups and undocumented Asian American caregivers may continue to experience mental and physical strains.

\section{Recommendations for Research, Professionals, and Policy on Asian American Caregivers}

The intertwined Asian American caregiving issues (the health impacts of the caregiving process, Asian American identity, the U.S. caregiving policy) play a role in the caregiving process. Researchers who only recognize Asian Americans as one racial entity may be unable to view Asian American caregivers' health from multiple perspectives. It is recommended that researchers observe caregivers from different Asian American subgroup populations and also explore different social determinants of health. It is expected that researchers can not only move closer to addressing Asian American caregivers' health, they can also help empower Asian American caregivers by recognizing their existence and their caregiving actions.

Addressing issues related to the impacts of caregiving on the health of Asian American caregivers is crucial. One of the recommendations for researchers is to design an instrument that can assess multiple dimensions of Asian American caregivers, including cultural behavior, social resources, gender roles, and perception about health and illness (Kim, 2009). Further, the majority of the Asian American population is foreign-born (U.S. Census Bureau, 2017). Thus, it would be beneficial for future studies to examine the relationships between immigration and family-related factors such as marital status and gender roles on the health and quality of life (e.g., mental health and physical functioning) among Asian American caregivers (Walton \& Takeuchi, 2010). As a part of culturally sensitive policy, programs, and services, it is ideal to have bilingual and bicultural professionals or those who understand Asian culture. However, having bilingual and bicultural professionals may not always be possible. Thus, professionals are asked to gain knowledge by participating in cultural competency training and workshops (Miyawaki, 2016). Moreover, rates of acculturation vary across Asian American groups, within an Asian American group, and among members of a family (Chun et al., 2002; Suinn et al., 1987). Hence, professionals need to take into consideration family dynamics and generational positions that influence Asian American ethnic identity and communication between caregivers and care recipients (Paik et al., 2016).

Another crosscutting issue is the possibility of having identity conflicts between caregivers and care recipients as well as between Asian traditions and Western values. Professionals need to incorporate cultural sensitivity into their interventions (Berkman, 2006). For example, Japanese Americans may not physically express their stress and depression, so practitioners may misdiagnose their health issues (Berkman, 2006). Further, Asian American caregivers may also employ Eastern traditions in treatments. For instance, Chinese Americans and Filipino Americans may use Eastern medication (Berkman, 2006; McLaughlin \& Braun, 1998; Vega, 2014) and Vietnamese Americans may use meditation as their daily habit (Braun \& Browne, 1998). Thus, professionals can design their caregiving interventions specifically tailored for a certain Asian American caregiver group or individual to improve their coping skills and quality of life (Nápoles et al., 2010). Similarly, researchers also need to be sensitive to Asian American cultural factors in their research. For example, future 
research may observe the association of socioeconomic and language barriers to different types of coping mechanisms (Nápoles et al., 2010).

The last crosscutting issue is that current U.S. federal caregiving policies do not adequately accommodate Asian American caregivers' needs and Asian cultural values. Even though Asian Americans have participated in U.S. public policy, the voice of Asian Americans is still underrepresented in policymaking (Chen \& Philip, 2009). It is recommended that Asian Americans become more engaged in politics to provide testimony in hearings (Chen \& Philip, 2009). Federal policies have been designed broadly in scope with an assumption to create neutral policies (Rosenbaum et al., 2000). However, the implementation of seemingly neutral policies disproportionately excludes individuals of racial minority groups with their eligibility criteria that prohibit certain individuals from participating in the programs (Rosenbaum et al., 2000). The NFCSP may appear to help Asian American caregivers by providing grants. However, Asian American ethnic groups cannot take advantage of the policy benefits due to the limited choices of services, language barriers, and ineligibility to meet the program requirements, such as having U.S. citizenship status. Fix and Laglagaron (2003) state that non-citizens pay taxes just as their U.S. citizen counterparts; and, thus, they suggest accessing public benefits should be based on legal resident status rather than citizenship status. Therefore, developing an amendment that allows family caregivers with legal resident status who have paid taxes to be eligible for the welfare benefits is recommended. As Fix and Laglagaron (2003) explained, providing equal social services between citizen and non-citizen can promote social integration and reduce national-origin discrimination.

\section{Conclusion}

Increasing studies and interest in assessing the health of Asian American family caregivers should be supported. Yet, one fundamental issue remains visible: key actors who hold essential roles in addressing public issues continue to treat Asian American caregivers from multiple ethnic groups as one large racial entity. A large part of aggregating Asian American populations is believed to be on researchers' shoulders. Researchers often apply the principle of parsimony to simplify a phenomenon, in this case the diversity of Asian Americans, including the heterogeneity of Asian American caregivers. Consequently, crosscutting issues of social determinants of health (the impacts of the caregiving process, identity conflicts, and a lack of adequate U.S. caregiving policy that supports ethnically diverse caregivers) are critically needed to be addressed. Paying attention to ethnically diverse Asian American caregivers and understanding the multiple dimensions of social determinants of health in research and practice may help Asian American caregivers maintain their health and improve their quality of life. Since culture, immigration history, and other sociodemographic characteristics of each Asian American subgroup are distinctive, lumping all ethnic populations into one racial group in research and practice demonstrates social injustice. Observing Asian Americans across ethnic groups, creating culturally sensitive caregiving interventions, and considering immigration and other imminent cultural issues in U.S. caregiving policy and programs can help reduce social injustice toward Asian American caregivers.

Disclosure Statement: The authors declare no conflicts of interest.

Ethics Approval Statement: The project is developed as a comprehensive literature review article and the project does not meet the regulatory definition of human subjects research. IRB review and approval of the research from the University's Office of Regulatory and Research Compliance are not required. 


\section{References}

AAPI Data (2017). One out of every 7 Asian immigrants is undocumented. AAPI Data. http://aapidata.com/blog/asian-undoc-1in7/

AARP (2014). Caregiving among Asian Americans and Pacific Islanders age 50+. AARP. https://www.aarp.org/content/dam/aarp/research/surveys_statistics/general/2014/caregivingamong-asian-americans-and-pacific-islanders-age-50-plus.doi.10.26419\%252Fres.00092.001.pdf

Administration for Community Living (ACL). (2017). National Family Caregiver Support Program (NFCSP) Process Evaluation. Administration for Community Living. https://www.acl.gov/sites/default/files/programs/2017-02/NFCSP Final Report-briefing.pdf

Administration for Community Living (ACL). (2019). National Family Caregiver Support Program. Administration for Community Living. https://www.acl.gov/programs/support-caregivers/nationalfamily-caregiver-support-program

Ahmad, F. Z., \& Weller, C. E. (2014). Reading between the data: The incomplete story of Asian Americans, Native Hawaiians, and Pacific Islanders. Center for American Progress. https://cdn.americanprogress.org/wp-content/uploads/2014/03/AAPI-report.pdf

Apesoa-Varano, E. C., Tang-Feldman, Y., Reinhard, S. C., Choula, R., \& Young, H. M. (2015). Multi-cultural caregiving and caregiver interventions: A look back and a call for future action. Generations, 39(4), $39-48$.

Asian Community Center Senior Services (ACCSV) (2019). Asian Community Center Senior Services. https://www.accsv.org

Berkman, B. (Ed.). (2006). Handbook of social work in health and aging. Oxford University Press.

Braun, K. L., \& Browne, C. V. (1998). Perceptions of dementia, caregiving, and help seeking among Asian and Pacific Islander Americans. Health \& Social Work, 23(4), 262-274. https://doi.org/10.1093/hsw/23.4.262

Broder, T., Moussavian, A., \& Blazer, J. (2015). Overview of immigrant eligibility for federal programs. National Immigration Law Center (NILC). https://www.nilc.org/issues/economic-support/overviewimmeligfedprograms/

Center for Migration Studies (CMS). (n.a.). State-Level unauthorized population and eligible-to-naturalize estimates. Center for Migration Studies (CMS). http://data.cmsny.org/

Chinese Community Center (2019). Chinese Community Center. https://ccchouston.org/caregiver/

Chen, K. Y. \& Philip, C. L. (2009). Asian American activism, advocacy, and public policy. In N. Tewari \& A. N. Alvarez (Eds.). Asian American psychology: Current perspectives (483-498). Taylor \& Francis.

Chu, J. P., \& Sue, S. (2011). Asian American mental health: What we know and what we don't know. Online Readings in Psychology and Culture, 3(1). https://doi.org/10.9707/2307-0919.1026

Chun, K. M., Organista, P. B., \& Marín, G. (Eds.) (2002). Acculturation: Advances in theory, measurement, and applied research. American Psychological Association.

Family Caregiver Alliance (FCA). (2004). The state of the states in family caregiver support: A 50-state study. Family Caregiver Alliance. https://www.caregiver.org/sites/caregiver.org/files/pdfs/50 state report complete.pdf

Feinberg, L. F. (2016). The dual pressures of family caregiving and employment-Six in 10 family caregivers are in the labor force. AARP Public Policy Institute. 
https://www.aarp.org/content/dam/aarp/ppi/2016-03/The-Dual-Pressures-off-Family-Caregivingand-Employment.pdf

Fitz, M., \& Glynn, S. J. (2012). Separating fact from fiction about the Child Tax Credit. Center for American Progress. https://www.americanprogress.org/issues/immigration/news/2012/05/30/11579/separating-factfrom-fiction-about-the-child-tax-credit/

Fix, M., \& Laglagaron, L. (2003). Social rights and citizenship: An international comparison. Urban Institute. https://www.urban.org/sites/default/files/publication/60531/410545-Social-Rights-andCitizenship.PDF

Flores, G., \& Brotanek, J. (2005). The healthy immigrant effect: A greater understanding might help us improve the health of all children. Archives of Pediatrics \& Adolescent Medicine, 159(3), 295-297. https://doi.org/10.1001/archpedi.159.3.295

Fuller-Thompson, E., \& Chi, M. (2012). Older Asian Americans and Pacific Islanders with Activities of Daily Living (ADL) limitations: Immigration and other factors associated with institutionalization. International Journal of Environmental Research and Public Health, 9(9), 3264-3279. https://doi.org/10.3390/ijerph9093264

Goode, W. J. (1960). A theory of role strain. American Sociological Review, 25(4), 483-496. https://doi.org/10.2307/2092933

Gordon, M. M. (1964). Assimilation in American life: The role of race, religion, and national origins. Oxford University Press.

Greater Boston Chinese Golden Age Center (GBCGAC) (2012). Greater Boston Chinese Golden Age Center. https://gbcgac.org/

Hobbs F., \& Stoops, N. (2002). Demographic Trends in the 2oth Century-Census 2000 Special Reports. U.S. Census Bureau. https://www.census.gov/prod/2002pubs/censr-4.pdf

Hoeffel, E. M., Rastogi, S., Kim, M. O., \& Shahid, H. (2012). The Asian population: 2010-201o Census Briefs. United States Census Bureau. https://www.census.gov/prod/cen2010/briefs/c2010br-11.pdf

Holland, A. T., \& Palaniappan, L. P. (2012). Problems with the collection and interpretation of AsianAmerican health data: Omission, aggregation, and extrapolation. Annals of Epidemiology, 22(6), 397-405. https://doi.org/10.1016/j.annepidem.2012.04.001

Holland, J. M., Thompson, L. W., Tzuang, M., \& Ghallagher-Thompson, D. (2010). Psychosocial factors among Chinese American women dementia caregivers and their association with salivary cortisol: Results of an exploratory study. Ageing International, 35, 109-127. https://doi.org/10.1007/s12126$\underline{010-9057-0}$

Illegal Immigration Reform and Immigrant Responsibility Act of 1996 (IIRIRA), P.L. 104-208, 104th Congress (1996, September 30). Illegal Immigration Reform and Immigrant Responsibility Act of 1996. https://www.uscis.gov/sites/default/files/ocomm/ilink/o-0-0-10948.html\#0-0-0-1335

Internal Revenue Service (IRS). (2018). Topic Number 602-Child and Dependent Care Credit. Internal Revenue Service. https://www.irs.gov/taxtopics/tc602

James, E., Hughes, M., \& Rocco, P. (2016). Addressing the needs of caregivers at risk: A new policy strategy. The Stern Center for Evidence-Based Policy-University of Pittsburgh. https://www.healthpolicyinstitute.pitt.edu/sites/default/files/CaregiverRiskPolicyStrategy April201 $\underline{6}$ o.pdf 
Kandil, C. Y. (2018). After 50 years of "Asian American," advocates say the term is "more essential than ever.” NBC News. https://www.nbcnews.com/news/asian-america/after-50-years-asian-americanadvocates-say-term-more-essential-n875601

Kentucky Cabinet for Health and Family Services (CHFS). (2009). Caregiver Support Services. Kentucky Cabinet for Health and Family Services. https://chfs.ky.gov/agencies/dail/Pages/caregiversupport.aspx

Kim, B. S. K. (2009). Acculturation and enculturation of Asian Americans. In N. Tewari \& A. N. Alvarez (Eds.). Asian American psychology: Current perspectives (pp. 97-112). Taylor \& Francis.

Kim, J. (1981). Processes of Asian American identity development: A study of Japanese American women's perceptions of their struggle to achieve positive identities as Americans of Asian Ancestry [Unpublished doctoral dissertation]. University of Massachusetts Amherst. https://scholarworks.umass.edu/cgi/viewcontent.cgi?referer=https://www.google.com/\&httpsredir= 1 \&article $=4686 \&$ context $=$ dissertations 1

Kim, J-H., \& Knight, B. G. (2008). Effects of caregiver status, coping styles, and social support on the physical health of Korean American caregivers. The Gerontologist, 48(3), 287-299. https://doi.org/10.1093/geront/48.3.287

Kitano, H. H., \& Nakaoka, S. (2001). Asian Americans in the twentieth century. Journal of Human Behavior in the Social Environment, 3(3-4), 7-17. https://doi.org/10.1300/J137vo3no3_02

Knight, B. G., \& Sayegh, P. (2010). Cultural values and caregiving: The updated sociocultural stress and coping model. Journal of Gerontology: Psychological Sciences, 65B(1), 5-13. https://doi.org/10.1093/geronb/gbpog6

Kurien, P. (2018). Who are Asian Americans? In R. C. Leong (Ed.). Asian American matters-A New York anthology (pp. 25-28). Asian American Research Institute-The City University of New York.

Lee, Y., \& Smith, L. (2012). Qualitative research on Korean American dementia caregivers' perception of caregiving: Heterogeneity between spouse caregivers and child caregivers. Journal of Human Behavior in the Social Environment, 22(2), 115-129. https://doi.org/10.1080/10911359.2012.646840

Liu. D., Hinton, L., Tran, C., Hinton, D., \& Barker, J. C. (2008). Reexamining the relationships among dementia, stigma, and caregiving in immigrant Chinese and Vietnamese family caregivers. Journal of Cross-Cultural Gerontology, 23(3), 283-299. https://doi.org/10.1007/s10823-008-9075-5

López, G., Ruiz, N. G., \& Patten, E. (2017). Key facts about Asian Americans, a diverse and growing population. Pew Research Center. http://www.pewresearch.org/fact-tank/2017/o9/o8/key-factsabout-asian-americans/

McLaughlin, L. A., \& Braun, K. L. (1998). Asian and Pacific Islander cultural values: Considerations for health care decision making. Health \& Social Work, 23(2), 116-126. https://doi.org/10.1093/hsw/23.2.116

Meyer, O. L., Nguyen, K. H., Dao, T. N., Vu, P., Arean, P., \& Hinton, L. (2015). The sociocultural context of caregiving experiences for Vietnamese dementia family caregivers. Asian American Journal of Psychology, 6(3), 263-272. https://doi.org/10.1037/aapoo00024

Miyawaki, C. E. (2016). Caregiving practice patterns of Asian, Hispanic, and Non-Hispanic White American family caregivers of older adults across generations. Journal of Cross-Cultural Gerontology, 31(1), 355. https://doi.org/10.1007/s10823-016-9281-5

Miyawaki, C. E. (2017). Association of filial responsibility, ethnicity, and acculturation among Japanese American family caregivers of older adults. Journal of Applied Gerontology, 36(3), 296-319. https://doi.org/10.1177/0733464815581484 
Nápoles, A. M., Chadiha, L., Eversley, R., \& Moreno-John, G. (2010). Reviews: Developing culturally sensitive dementia caregiver interventions: Are we there yet? American Journal of Alzheimer's Disease and Other Dementias, 25(5), 389-406. https://doi.org/10.1177/1533317510370957

National Association of Social Workers (NASW). (2010). NASW standards for social work practice with family caregivers of older adults. National Association of Social Workers. https://www.socialworkers.org/LinkClick.aspx?fileticket=aUwQL98exRM\%3D\&portalid=0

National Family Caregiver Support Act. (2000). Part E-National Family Caregiver Support Program, Pub. L. 106-501, title III, Nov. 13, 2000, 114 Stat. 2253.

http://uscode.house.gov/view.xhtml?path=/prelim@title42/chapter35/subchapter3/partE\&edition= prelim

Paik, S. J., Choe, S. M. M., \& Witenstein, M. A. (2016). Filipinos in the U.S.: Historical, social, and educational experiences. Social and Educational History, 5(2), 134-160. http://dx.doi.org/10.17583/hse.2016.2062

Radford, J. (2019). Key findings about U.S. immigrants. Pew Research Center. https://www.pewresearch.org/fact-tank/2019/06/17/key-findings-about-u-s-immigrants/

Roberts, A. W., Ogunwole, S. U., Blakeslee, L., \& Rabe, M. A. (2018). The population 65 years and older in the United States: 2016. American Community Survey Reports. https://www.census.gov/content/dam/Census/library/publications/2018/acs/ACS-38.pdf

Rosenbaum, S., Markus, A. R., \& Darnell, J. (2000). U.S. civil rights policy and access to health care by minority Americans: Implications for a changing health care system. Medical Care Research and Review, 57(Suppl. 1), 236-259. https://doi.org/10.1177/1077558700057001S11

Schulz, R., \& Eden, J. (Eds.). (2016). Families caring for an aging America. National Academies Press. https://www.ncbi.nlm.nih.gov/books/NBK396411/

Shih, K. Y., Chang, T. F., \& Chen, S. Y. (2019). Impacts of the model minority myth on Asian American individuals and families: Social justice and critical race feminist perspectives. Journal of Family Theory \& Review, 11(3), 412-428. https://doi.org/10.1111/jftr.12342

Shyong, F. (2020). On a new podcast about Asian American identity, we talk about the struggle to feel we're “enough.” Los Angeles Times. https://www.latimes.com/california/story/2020-03-10/asian-enoughwhy

Sieber, S. (1974). Toward a theory of role accumulation. American Sociological Review, 39(4), 567-578. https://doi.org/10.2307/2094422

Suinn, R. M., Rickard-Figueroa, K., Lew, S., \& Vigil, P. (1987). The Suinn-Lew Asian Self-Identity Acculturation Scale: An initial report. Educational and Psychological Measurement, 47, 401-407. https://doi.org/10.1177/0013164487472012

Takamura, J. C. (1991). Asian and Pacific Islander elderly. In N. Mokuau (Ed.), Handbook of social services for Asians and Pacific Islanders (pp. 185-202). Greenwood Press.

Takeuchi, D. T., Hong, S., Gile, K., \& Alegría, M. (2007). Developmental contexts and mental disorders among Asian Americans. Research in Human Development, 4(1), 49-69. https://doi.org/10.1080/15427600701480998

Taxpayer Relief Act of 1997. (1997). Pub. L. 105-134, Aug. 5, 1997, https://www.govinfo.gov/content/pkg/PLAW-105publ34/pdf/PLAW-105publ34.pdf

The National Alliance for Caregiving (NAC) and the AARP Public Policy Institute. (2004). Caregiving in the U.S. The National Alliance for Caregiving (NAC) and the AARP Public Policy Institute. https://assets.aarp.org/rgcenter/il/us caregiving.pdf 
The National Alliance for Caregiving (NAC) and the AARP Public Policy Institute. (2015). Caregiving in the U.S. 2015. The National Alliance for Caregiving (NAC) and the AARP Public Policy Institute. https://www.aarp.org/content/dam/aarp/ppi/2015/caregiving-in-the-united-states-2015-reportrevised.pdf

U.S. Census Bureau. (2017). 2017 American Community Survey 1-Year Estimates. U.S. Census Bureau. https://www.census.gov/programs-surveys/acs/news/data-releases/2017/release.html

Vega, T. (2014). As parents age, Asian-Americans struggle to obey a cultural code. The New York Times. https://www.nytimes.com/2014/01/15/us/as-asian-americans-age-their-children-face-culturalhurdles.html

Walton, E., \& Takeuchi, D. T. (2010). Family structure, family processes, and well-being among Asian Americans: Considering gender and nativity. Journal of Family Issues, 31(3), 301-332. https://doi.org/10.1177/0192513X09350873

West, L. A., Cole, S., Goodkind, D., \& He, W. (2014). 65+ in the United States: 2010. Current Population Reports. United States Census Bureau. https://www.census.gov/content/dam/Census/library/publications/2014/demo/p23-212.pdf

Xia, Y. R., Do, K. A., \& Xie, X. (2013). The adjustment of Asian American families to the U.S. context: The ecology of strengths and stress. In G. W. Peterson \& K. R. Bush (Eds.), Handbook of marriage and the family (pp. 705-722). Springer. https://doi.org/10.1007/978-1-4614-3987-5_29

Xu, L., Tang, F., Li, L. W., \& Dong, X. Q. (2017). Grandparent caregiving and psychological well-being among Chinese American older adults-The roles of caregiving burden and pressure. Journals of Gerontology Series A: Biomedical Sciences and Medical Sciences, 72(suppl_1), S56-S62. https://doi.org/10.1093/gerona/glw186

Zane, N., \& Mak, W. (2002). Major approaches to the measurement of acculturation among ethnic minority populations: A content analysis and an alternative empirical strategy. In K. M. Chun, P. B. Organista, \& G. Marín, (Eds.). Acculturation: Advances in theory, measurement, and applied research. American Psychological Association.

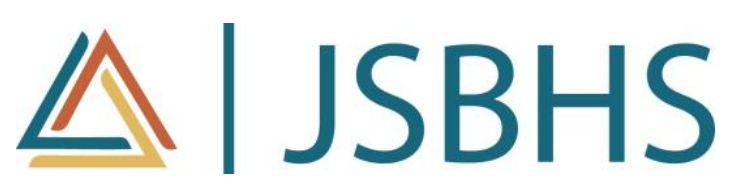

The Journal of Social, Behavioral, and Health Sciences (JSBHS), co-sponsored by the College of Health Sciences and the College of Social and Behavioral Sciences at Walden University, is a peer-reviewed, online, interdisciplinary journal focusing on theoretically-based research that addresses contemporary national and international issues. JSBHS articles include peer-reviewed research reports, brief reports, comprehensive literature reviews, books reviews, and student research. 